\title{
Shortcuts in Esthetic Dentistry
}

Author: Ronaldo Hirata

Publisher: Quintessence Publishing, Germany

Language: English

ISBN: 978-85-7889-111-4

Edition: 2/e

Publish Year: 2017

Pages: 686, illustrated

Price: $240.00 €$

\section{SHORTCUTS}
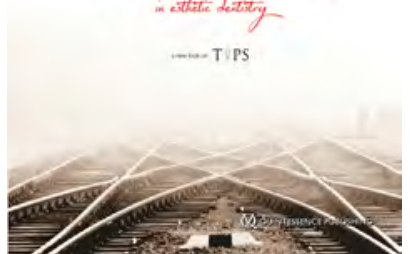

In the five chapters of the book entitled "Shortcuts in Esthetic Dentistry. A new look on TIPS", Dr. Ronaldo Hirata reveals simple and practical solutions to common questions and problems in order to cope with the difficulties of aesthetic restorative dentistry. Each chapter is based on a series of questions the reader can ask and the author answers in detail on the basis of the latest scientific evidence and eloquent case presentations.

The questions raised by dental bleaching, such as concepts of bleaching substances are given pertinent answers and edifying cases are presented. The second chapter covers composite resins, longevity and maintenance of composite restorations and adhesive systems to perform operative and restorative dentistry. Questions about esthetic restorations and previous makeovers, why and how, a simpler way and where science is going are provided with specific rules for each clinical situation in the next chapter.

The last two chapters address the topic of esthetic restorations and sculpture in posterior teeth and inlays and onlays, such as indirect partial restorations in composites and ceramics where they give the most relevant examples and many useful insights.

Throughout the book, the author makes a presentation of the steps of the simplified procedures, providing the reader with advice on how to implement the concepts described.

Clinicians will frequently return to "Shortcuts in Esthetic Dentistry", a book that is exceptionally illustrated by the 2,800 figures, because they find effective solutions for their clinical practice covering the most common problems raised by contemporary aesthetic dentistry.

DOI: 10.25241/stomaeduj.2018.5(2).bookreview.2

Iulia

\section{Ciolachi}

DMD

Holistic Dental \& Medical Institute of Bucharest-ROPOSTURO, Bucharest Romania

e-mail:dr.iuliaciolachi@yahoo.ro 